\title{
Centrifuge modelling of building response to tunnel excavation
}

\author{
Stefan Ritter MSC \\ PhD Researcher, Department of Engineering, University of Cambridge, \\ Cambridge, UK (corresponding author: sr671@cam.ac.uk) \\ (Orcid:0000-0002-1465-6081) \\ Giorgia Giardina MSc, PhD \\ Lecturer, Department of Architecture and Civil Engineering, \\ University of Bath, Bath, UK
}

\author{
Matthew J. DeJong MSc, PhD \\ Senior Lecturer, Department of Engineering, University of Cambridge, \\ Cambridge, UK \\ Robert J. Mair MA, PhD, CBE, FREng, FICE, FRS \\ Professor Lord, Department of Engineering, University of Cambridge, \\ Cambridge, UK
}

Understanding the building response to tunnelling-induced settlements is an important aspect of urban tunnelling in soft ground. Previous centrifuge modelling research demonstrated significant potential to study this tunnel-soilstructure interaction problem. However, these recent studies were limited by simplified building models, which might result in uncertainties when interpreting the building performance to tunnelling subsidence. This paper presents an experimental modelling procedure and the results of a series of centrifuge tests, involving relatively complex surface structures subjected to tunnelling in sand. Powder-based three-dimensional (3D) printing was adopted to fabricate building models with realistic layouts, facade openings and foundations. The 3D printed material had a Young's modulus and a brittle response similar to historic masonry. Modelling effects and boundary conditions are quantified. The good agreement between the experimentally obtained results and previous research demonstrates that the soil-structure interaction during tunnel excavation is well replicated. The experimental procedure provides a framework to quantify how building features affect the response of buildings to tunnelling subsidence.

\section{Notation}

C depth of tunnel cover

$D \quad$ tunnel diameter

$D R \quad$ deflection ratio

$E \quad$ Young's modulus of building

$E_{\mathrm{s}} \quad$ secant soil stiffness

$e \quad$ eccentricity

g acceleration due to gravity

hog hogging

I second moment of area

$L \quad$ building length

$M \quad$ modification factor

$O \quad$ openings

$s \quad$ slope

sag sagging

su spin-up

$V_{1, \mathrm{~s}} \quad$ surface soil volume loss

$V_{1, \mathrm{t}} \quad$ tunnel volume loss

$\Delta \quad$ deflection

$\delta \quad$ vertical displacements

$\varepsilon_{\mathrm{h}} \quad$ horizontal building strain

$\rho \quad$ relative building bending stiffness

$\sigma_{\mathrm{h}} \quad$ horizontal soil stress at rest

$\sigma_{\mathrm{t}} \quad$ internal tunnel pressure

$\sigma_{\mathrm{v}} \quad$ vertical soil stress

\section{Introduction}

Creating urban underground space frequently involves the construction of shallow tunnels underneath highly congested urban areas. These tunnelling activities inherently induce ground movements that cause complex interaction between the adjacent buildings and the ground (Burd et al., 2000). Understanding this interaction is particularly important for masonry buildings, which can be susceptible to damage due to differential settlement, causing non-linear behaviour of both the structure and the soil.

Several case studies (Dimmock and Mair, 2008; Fargnoli et al., 2015; Farrell et al., 2011; Frischmann et al., 1994; Viggiani and Standing, 2001) have shown that tunnellinginduced soil displacements beneath buildings are radically different than for a greenfield site. Computational modelling studies (Franzius et al., 2006; Goh and Mair, 2011; Melis and Rodriguez Ortiz, 2001; Potts and Addenbrooke, 1997; Son and Cording, 2007) identified that the building stiffness plays a key role when investigating the response of surface structures subjected to tunnelling. This finding is supported by the results of centrifuge modelling (Caporaletti et al., 2005; Farrell, 2010; Farrell and Mair, 2012; Taylor and Grant, 1998; Taylor and Yip, 2001), which captures the correct self-weight stress-strain behaviour of the soil and the surface structure.

Although these centrifuge tests provided useful information on the general behaviour of a simplified structure during the tunnel excavation procedure, they made no attempt to investigate the influence of building features; structural details such as a realistic building layout, facade openings and foundations were not considered. The main reason for this limitation is that 
in centrifuge modelling large-scale factors of between 1:20 and 1:100 are used (Knappett et al., 2010). Replicating building details at a small scale is a challenge, and centrifuge modelling research so far has focused on replicating the building stiffness rather than other important building features.

Likewise, recent investigations at $1 \boldsymbol{g}$ have not included building details such as facade openings (Al Heib et al., 2013; Shahin et al., 2011) or the three-dimensional (3D) building layout (Giardina et al., 2012; Kim et al., 2006; Shahin et al., 2011). In addition, these $1 g$ investigations inherently have limitations in replicating realistic soil-structure interaction. Ignoring building details can result in uncertainty when assessing tunnelling effects on nearby structures, which has been highlighted in computational studies (Giardina et al., 2015b; Melis and Rodriguez Ortiz, 2001; Pickhaver et al., 2010; Son, 2015; Son and Cording, 2005). However, there is a lack of experimental data to evaluate computational models.

Advances in 3D printing (3DP) have opened the door to an array of applications in civil engineering research (DeJong and Vibert, 2012; Feng et al., 2015; Liang et al., 2013, 2015). The main advantage of using 3DP to centrifuge modelling is that small-scale models can be fabricated without missing essential details. For instance, Liang et al. (2015) have used 3D printed root models when centrifuge modelling the seismic performance of vegetated slopes.

This paper presents a centrifuge modelling procedure to study representative building models subject to tunnelling-induced ground movements, such as discussion of modelling details, modelling effects and validity compared with previous research. Details and the material properties of the $3 \mathrm{D}$ printed buildings are presented, setting a precedent for modelling surface structures above a tunnel in a geotechnical centrifuge. Modelling effects and boundary effects are discussed before comparing example results of the tunnel excavation simulation to previous literature. These results demonstrate good agreement and realistic replication of tunnel-soil-structure interaction. Thus, the introduced modelling procedure provides a valuable framework to further explore the influence of building features on the response of structures to tunnelling subsidence.

\section{Experimental design}

\subsection{Introduction}

A series of centrifuge tests (Figure 1) on complex building models were performed on the geotechnical centrifuge at the University of Cambridge (Schofield, 1980). The tests differ in the location of the building model relative to the tunnel and the amount of facade openings (Table 1). The experiments were conducted at $75 \mathrm{~g}$ and a corresponding scale factor of

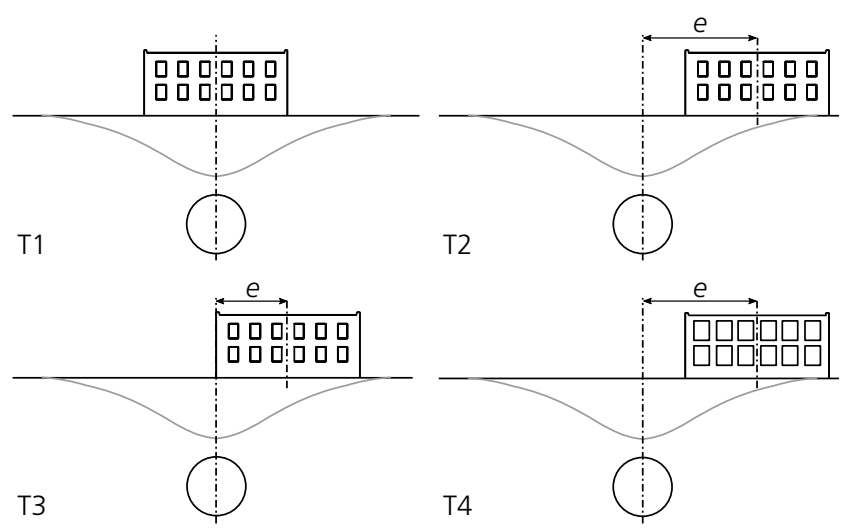

Figure 1. Centrifuge test series

Table 1. Variations between centrifuge tests in terms of the eccentricity of the centre of the building model from the tunnel centreline and the amount of facade openings

\begin{tabular}{|lcc|}
\hline Test & Eccentricity, e: $\mathbf{m m}$ & Openings, $\mathbf{0 :} \%$ \\
\hline T1 & 0 & 20 \\
T2 & 160 & 20 \\
T3 & 100 & 20 \\
T4 & 160 & 40 \\
\hline
\end{tabular}

1:75. The adopted strong box, soil model, model tunnel and model dimensions are based on that used by Farrell (2010). Marshall et al. (2012) have demonstrated that this experimental set-up resembles greenfield displacements for tunnels in sand. Recently, Farrell (2010) employed this experimental setup to study the response of aluminium, microconcrete and masonry beams to tunnelling subsidence (see also Farrell and Mair, 2012; Giardina et al., 2015a). Due to the similar tunnelling scenario modelled, these experiments provide a unique database to compare with the research on more representative building models described herein.

\subsection{Model geometry and instrumentation}

Figure 2 illustrates that the centrifuge model replicates a tunnelling scenario with a cover-to-diameter $(C / D)$ ratio of $1 \cdot 37$. A relatively shallow tunnel was modelled because building damage decreases with tunnel depth (Son, 2015; Vu et al., 2015). The front boundary of the strong box is a Perspex window while the base, side-walls and the back wall are made out of steel.

Figure 3 shows that three digital cameras (Canon PowerShot G10) were installed in front of the Perspex window to track ground and structure displacements using digital image correlation (DIC) and the software GeoPIV (White et al., 2003). In addition, laser displacement sensors (Baumer Electric OADM 12I6430/S35A) and Solartron linear variable 


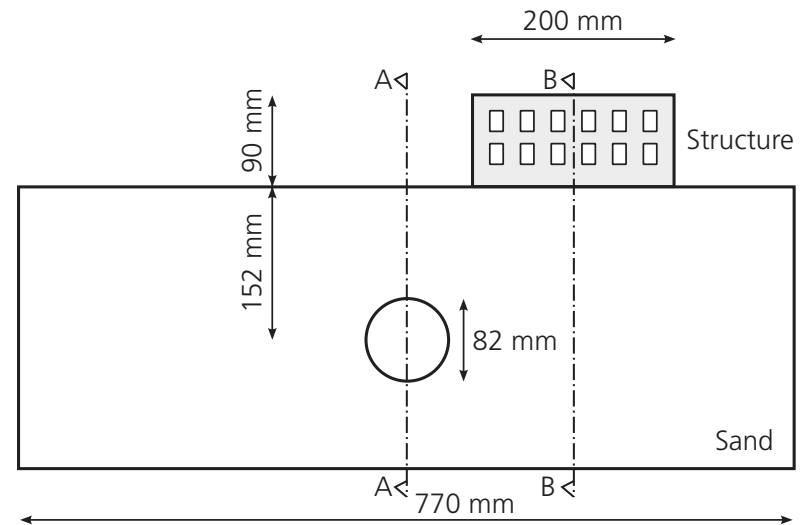

(a)

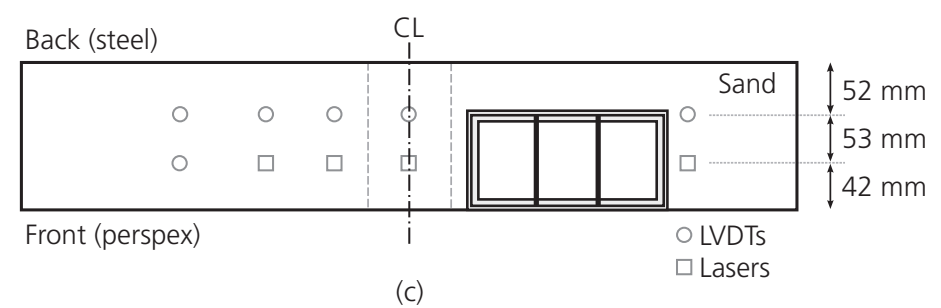

$\stackrel{100 \mathrm{~mm}}{\longrightarrow}$

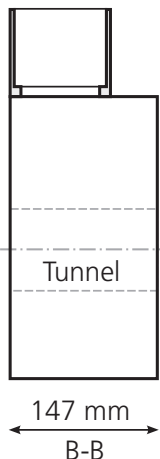

(b)

Figure 2. Centrifuge model: (a) front view, (b) cross-section B-B and (c) plan view. The set-up refers to the test T2

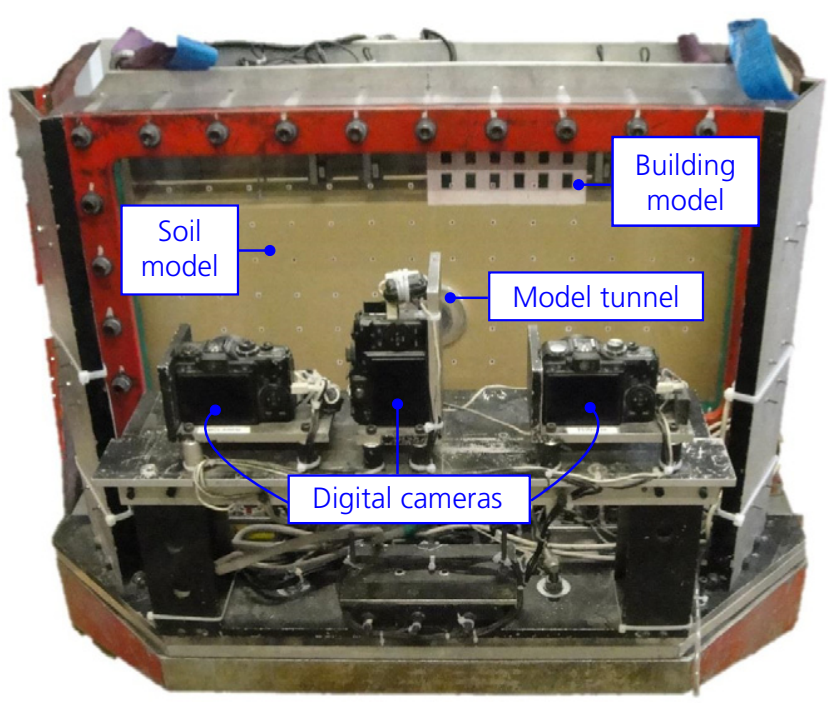

Figure 3. Front view of the centrifuge model indicating the image-based deformation measurement equipment

differential transformers (LVDTs) monitored surface soil settlements (Figure 2(c)). These surface settlement instruments enable a comparison to the GeoPIV results and thus provide an adequate degree of redundancy. Furthermore, boundary effects in the Perspex plane, caused by friction between the Perspex and the soil, can be quantified by comparing the data of the lasers and LVDTs with the GeoPIV results.

\subsection{Model tunnel and tunnel excavation simulation}

The tunnelling process is modelled by reducing the tunnel diameter to simulate schematically a ground loss (Farrell, 2010; Jacobsz, 2002; Loganathan et al., 2000; Mair et al., 1984; Marshall et al., 2012; Potts, 1976; Taylor and Grant, 1998; Taylor and Yip, 2001; Vorster, 2002). Figure 4 illustrates the model tunnel, which consists of a $1 \mathrm{~mm}$ thick Latex membrane with a diameter of $70 \mathrm{~mm}$ and a brass mandrill with an outer diameter of $60 \mathrm{~mm}$. The membrane is sealed to the circular end pieces of the brass mandrill (diameter of $80 \mathrm{~mm}$ ) using a wire, and the cavity between the brass cylinder and the membrane is filled with water until a tunnel diameter of $82 \mathrm{~mm}$ is obtained. To restrain the position of the model tunnel, the tunnel is fixed to the front and the back walls with brass fitting rings. To ensure uniform settlement along the length of the tunnel, including at the front and back of the soil box, the end of the model tunnel was set within a recess of the Perspex window (Figure 4(a)).

The tunnel diameter is reduced by withdrawing water from the tunnel using a tunnel control system (Figure 5). This system was first reported by Jacobsz (2002) and consists of a 
International Journal of Physical Modelling in Geotechnics Volume 18 Issue 3
Centrifuge modelling of building

response to tunnel excavation

Ritter, Giardina, DeJong and Mair

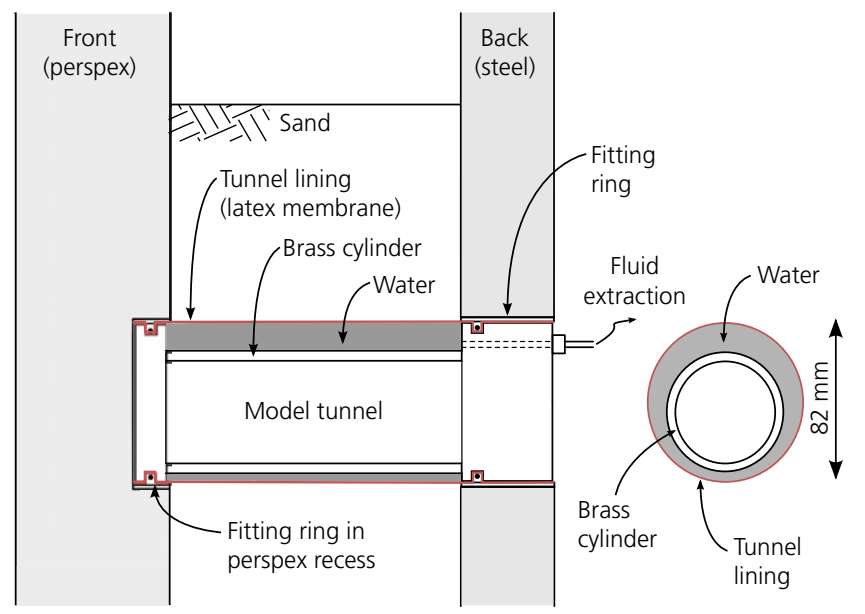

(a)

(b)

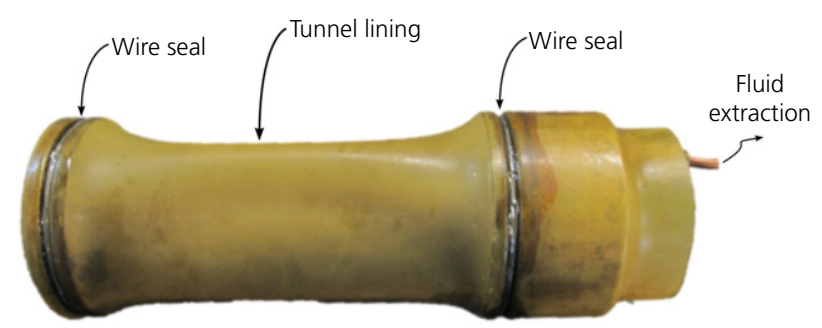

(c)

Figure 4. Model tunnel: (a) cross-section A-A (Figure 2(a)), (b) cross-section of model tunnel and (c) image of the model tunnel

standpipe, a solenoid valve, a linear actuator that moves a piston of a water-filled sealed cylinder, a pore water pressure transducer and $4 \mathrm{~mm}$ outer diameter copper pipes to connect these individual parts to the model tunnel. The tasks of the tunnel control system are twofold. First, during the acceleration of the centrifuge the standpipe is connected through the solenoid valve to the model tunnel. The constant water head of the standpipe results in a tunnel pressure that balances the vertical soil stresses at the tunnel axis to minimise soil displacements as the centrifuge accelerates. Section 3.1 discusses the implications of this technique. Second, after reaching $75 \mathrm{~g}$, the solenoid valve is closed and the volume of the tunnel is controlled by a piston. Calibration procedures determined that a piston movement of $2.5 \mathrm{~mm}$ was required to obtain a tunnel volume loss of $1.0 \%$. During the centrifuge test, the linear actuator is remotely controlled and the piston movement is monitored using a potentiometer to track the tunnel volume loss.

\subsection{Soil model and preparation}

For all centrifuge tests, dry silica sand known as Leighton Buzzard Fraction E (Table 2) was poured into the model with a relative density $\left(I_{\mathrm{R}}\right)$ of $90 \%( \pm 3 \%)$ using an automatic sand pourer (Madabhushi et al., 2006). To obtain a uniform soil

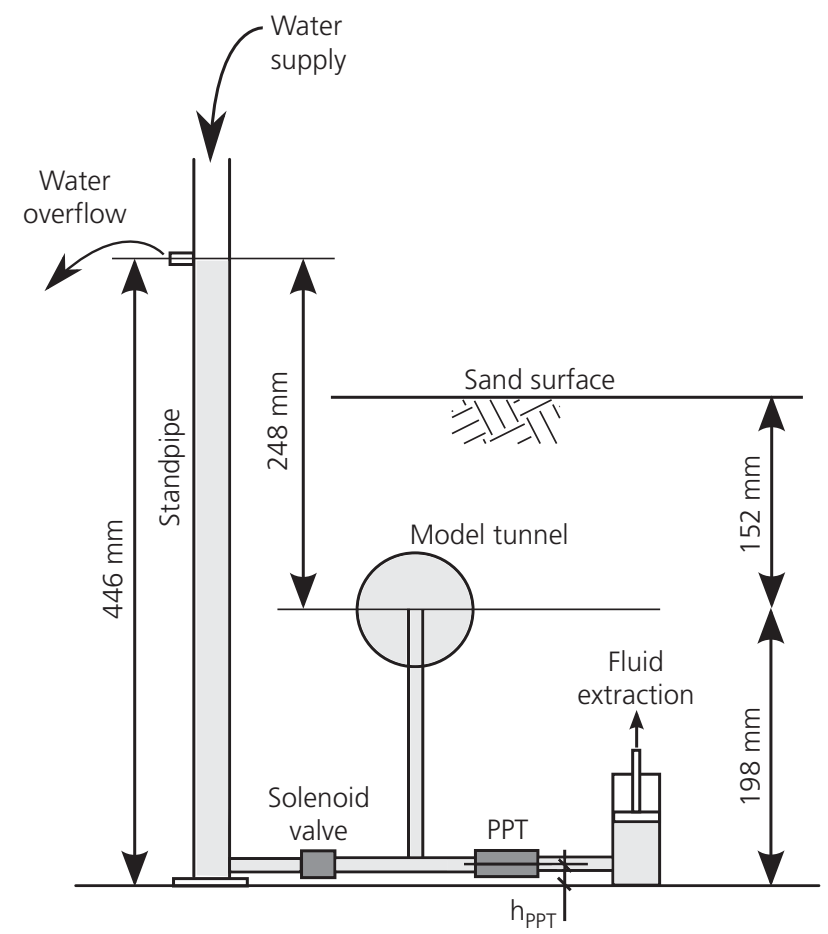

Figure 5. Tunnel control system

Table 2. Properties of Leighton Buzzard Fraction E silica sand (Tan, 1990)

\begin{tabular}{|lc|} 
Property & Value \\
\hline$D_{10}$ grain size: $\mathrm{mm}$ & 0.095 \\
$D_{50}$ grain size: $\mathrm{mm}$ & 0.14 \\
$D_{60}$ grain size: $\mathrm{mm}$ & 0.15 \\
Minimum voids ratio, $e_{\min }$ & 0.65 \\
Maximum voids ratio, $e_{\max }$ & 1.01 \\
Specific gravity, $G_{\mathrm{s}}$ & 2.67 \\
Critical state friction angle, $\phi_{\text {crit }}:$ deg & 32
\end{tabular}

density throughout the model, and in particular surrounding the model tunnel, the sand was poured with the model lying on the Perspex window and the model tunnel positioned in the recess of the Perspex window. A paper sleeve was placed surrounding the tunnel to avoid bulging of the Latex lining due to gravitational forces. This sleeve was incrementally lifted following the sand pouring progress. The reason for using a consistent very dense soil model is that the degree of building damage increases with the relative density of soil (Netzel, 2009; Son, 2015).

\subsection{Building models}

\subsubsection{DP}

Building models were fabricated using a powder-based 3DP technology (Sachs et al., 1990). The main principle of 3DP is 
International Journal of Physical Modelling in Geotechnics Volume 18 Issue 3
Centrifuge modelling of building

response to tunnel excavation

Ritter, Giardina, DeJong and Mair that droplets of a binder are jetted on a powder layer, which results in a solid cross-section of the structure surrounded by loose powder. A new layer of powder is then laid down, and this procedure is repeated until the final object is fabricated. Finally, the loose powder is removed and the solid object(s) can be extracted from the powder bed. Throughout this research, the building models consisted of the raw 3D printed material; post-printing treatment was not carried out. Feng et al. (2015) gives a detailed description of the adopted 3DP process.

The surface structures were $3 \mathrm{D}$ printed on a $\mathrm{Z}$ Corporation Zprinter350 using VisiJet PXL Core powder and VisiJet PXL Clear Binder. A constant layer thickness of $0.088 \mathrm{~mm}$ was used. The $3 \mathrm{D}$ printed material is characterised by a distinct orthotropic behaviour that is related to the orientation of the structure in the print bed (Asadi-Eydivand et al., 2016; Farzadi et al., 2014, 2015; Feng et al., 2015; Gharaie et al., 2013). The tensile strength of the untreated 3D printed materials is lowest in the direction perpendicular to these layers (Chan, 2012, 2013; Feng et al., 2015). To make use of this lower interlayer bond strength, the building model was printed on end - that is, with a rotation of $90^{\circ}$ (about the axis of the tunnel) when compared with its position in the centrifuge tests, as shown in Figure 6. Due to the size of the print bed, the building models were printed in two parts that were subsequently glued together using Araldite standard.

\subsubsection{Material properties}

Figure 6 also shows the model beam specimens that were printed in every print job and subsequently tested in four-point bending following ASTM D 790M-86 II, Procedure A (ASTM, 1986). These samples, $125 \mathrm{~mm} \times 4 \mathrm{~mm} \times 20 \mathrm{~mm}$, were tested flatwise with a support span of $99 \mathrm{~mm}$ and a load span of

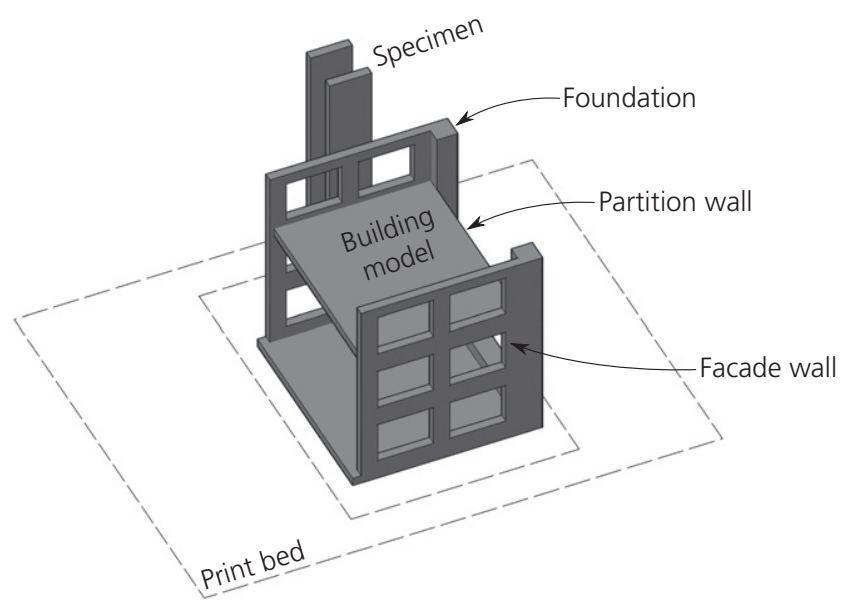

Figure 6. Orientation of building model and specimen in print bed
$33 \mathrm{~mm}$. A cross-head motion of $4.5 \mathrm{~mm} / \mathrm{min}$ was used and the mid-span deflection of the beams was monitored using a laser measurement device. Three unloading and loading cycles were carried out between 2 and 1 N. Figure 7 shows a representative stress-strain curve of the $3 \mathrm{D}$ printed material. The material exhibits a softening behaviour typical of brittle materials, and thus can be used to model cracking damage experimentally. Table 3 summarises the material properties for the model beam samples associated with each centrifuge test, and compares these results with typical masonry properties. The $3 \mathrm{D}$ printed material has a lower density than masonry, Young's modulus values comparable to historic masonry and a flexural strength and ultimate strain higher than masonry. To replicate typical global building stiffness values observed in the field, the building layout and facade openings were carefully adjusted. Figure 8 compares the building stiffness of the building models with case histories and previous centrifuge experiments. For predicting the bending stiffness, the opening reduction proposed by Melis and Rodriguez Ortiz (2001) was adopted; the neutral axis was located at the height of the centroid of the facade wall cross-section and for each building model the corresponding average Young's modulus value (Table 3) was used.

\subsubsection{Building features}

The aim of adopting 3DP is to replicate realistic building features. Figure 9 details the considered building characteristics, such as the building layout, strip foundations, a rough soilstructure interface and window openings. To obtain a realistic stress of about $100 \mathrm{kPa}$ beneath the foundation of the building walls transverse to the tunnel axis, dead load bars were placed on top of the buildings. The facade wall visible through the Perspex window was coloured to better enable the DIC.

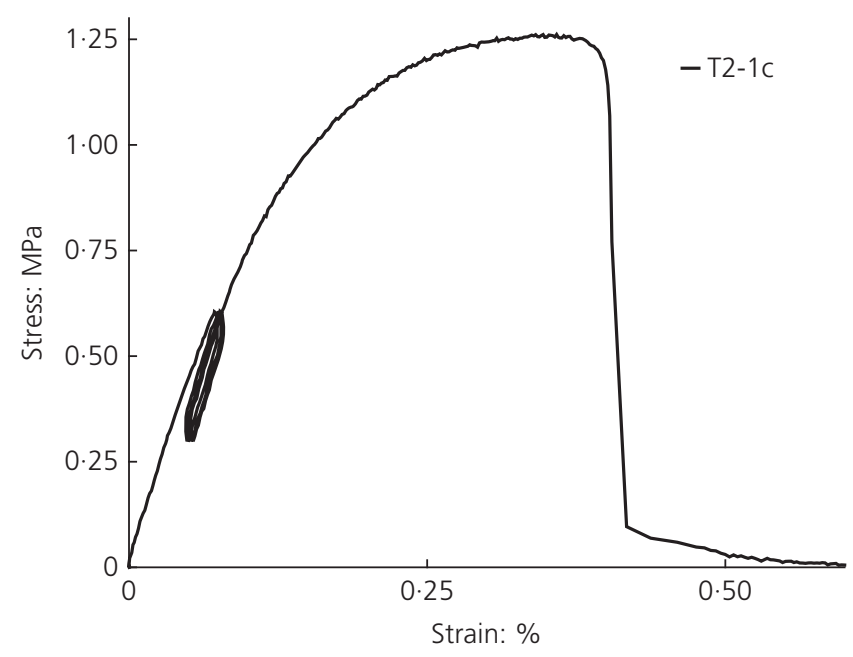

Figure 7. Stress-strain relationship of the 3D printed material: specimen T2-1c (Table 3) 
Table 3. Three-dimensional printed material properties compared with typical masonry properties from Giardina et al. (2015c). The variability in the material properties is measured by the standard deviation (SD)

\begin{tabular}{|c|c|c|c|c|c|c|c|c|c|c|c|c|c|}
\hline \multirow[b]{2}{*}{ Test } & \multirow[b]{2}{*}{ Samples } & \multicolumn{3}{|c|}{ Density: $\mathrm{kg} / \mathrm{m}^{3}$} & \multicolumn{3}{|c|}{ Flexural strength: $\mathrm{MPa}$} & \multicolumn{3}{|c|}{ Young's modulus: MPa } & \multicolumn{3}{|c|}{ Ultimate strain: \% } \\
\hline & & Value & Mean & SD & Value & Mean & SD & Value & Mean & SD & Value & Mean & SD \\
\hline \multirow[t]{4}{*}{ T1 } & $1 a$ & 1294 & \multirow{4}{*}{1293} & \multirow[t]{4}{*}{1.076} & $1 \cdot 502$ & \multirow[t]{4}{*}{$1 \cdot 362$} & \multirow[t]{4}{*}{$0 \cdot 100$} & $913 \cdot 3$ & \multirow[t]{4}{*}{$893 \cdot 1$} & \multirow[t]{4}{*}{$49 \cdot 1$} & 0.338 & \multirow[t]{4}{*}{0.298} & \multirow[t]{4}{*}{0.044} \\
\hline & $1 \mathrm{~b}$ & 1293 & & & $1 \cdot 343$ & & & $948 \cdot 0$ & & & 0.237 & & \\
\hline & $1 \mathrm{c}$ & 1293 & & & 1.337 & & & $877 \cdot 7$ & & & 0.319 & & \\
\hline & $1 d$ & 1292 & & & $1 \cdot 265$ & & & $833 \cdot 3$ & & & 0.298 & & \\
\hline \multirow[t]{4}{*}{$\mathrm{T} 2$} & $1 a$ & 1278 & \multirow[t]{4}{*}{1278} & \multirow[t]{4}{*}{$3 \cdot 338$} & $1 \cdot 330$ & \multirow[t]{4}{*}{$1 \cdot 311$} & \multirow[t]{4}{*}{0.073} & $815 \cdot 5$ & \multirow[t]{4}{*}{$800 \cdot 6$} & \multirow[t]{4}{*}{$50 \cdot 5$} & 0.310 & \multirow[t]{4}{*}{0.357} & \multirow[t]{4}{*}{0.038} \\
\hline & $1 b$ & 1275 & & & 1.405 & & & $861 \cdot 0$ & & & 0.404 & & \\
\hline & $1 c$ & 1279 & & & $1 \cdot 264$ & & & $784 \cdot 8$ & & & 0.358 & & \\
\hline & $1 d$ & 1283 & & & 1.246 & & & $741 \cdot 1$ & & & 0.354 & & \\
\hline \multirow[t]{4}{*}{ T3 } & $1 a$ & 1281 & \multirow[t]{4}{*}{1261} & \multirow[t]{4}{*}{$24 \cdot 81$} & 1.238 & \multirow[t]{4}{*}{$1 \cdot 130$} & \multirow[t]{4}{*}{$0 \cdot 161$} & $798 \cdot 7$ & \multirow[t]{4}{*}{$727 \cdot 4$} & \multirow[t]{4}{*}{$154 \cdot 5$} & 0.257 & \multirow[t]{4}{*}{0.282} & 0.044 \\
\hline & $1 \mathrm{~b}$ & 1284 & & & 1.289 & & & 907.5 & & & 0.270 & & \\
\hline & $1 \mathrm{c}$ & 1246 & & & 0.948 & & & $637 \cdot 1$ & & & 0.253 & & \\
\hline & $1 d$ & 1235 & & & 1.044 & & & $566 \cdot 5$ & & & 0.347 & & \\
\hline T4 & $1 \mathrm{a}$ & 1258 & 1272 & $10 \cdot 87$ & $0 \cdot 875$ & 0.934 & 0.051 & $460 \cdot 2$ & $515 \cdot 9$ & $39 \cdot 6$ & 0.359 & 0.352 & 0.034 \\
\hline & $1 b$ & 1270 & & & $0 \cdot 910$ & & & $530 \cdot 8$ & & & 0.320 & & \\
\hline & $1 \mathrm{c}$ & 1283 & & & 0.987 & & & $553 \cdot 0$ & & & 0.332 & & \\
\hline & $1 d$ & 1278 & & & 0.963 & & & $519 \cdot 6$ & & & 0.398 & & \\
\hline Total & & 1276 & & & $1 \cdot 184$ & & & $734 \cdot 4$ & & & 0.322 & & \\
\hline Total & & $16 \cdot 98$ & & & 0.197 & & & $163 \cdot 4$ & & & 0.050 & & \\
\hline Masc & & 1900 & & & $0.1-0.9$ & & & $1000-9000$ & & & $0.05^{\mathrm{a}}$ & & \\
\hline
\end{tabular}

aStrain at onset of cracking for brick walls (Burland and Wroth, 1974) 
International Journal of Physical Modelling in Geotechnics Volume 18 Issue 3
Centrifuge modelling of building

response to tunnel excavation

Ritter, Giardina, DeJong and Mair

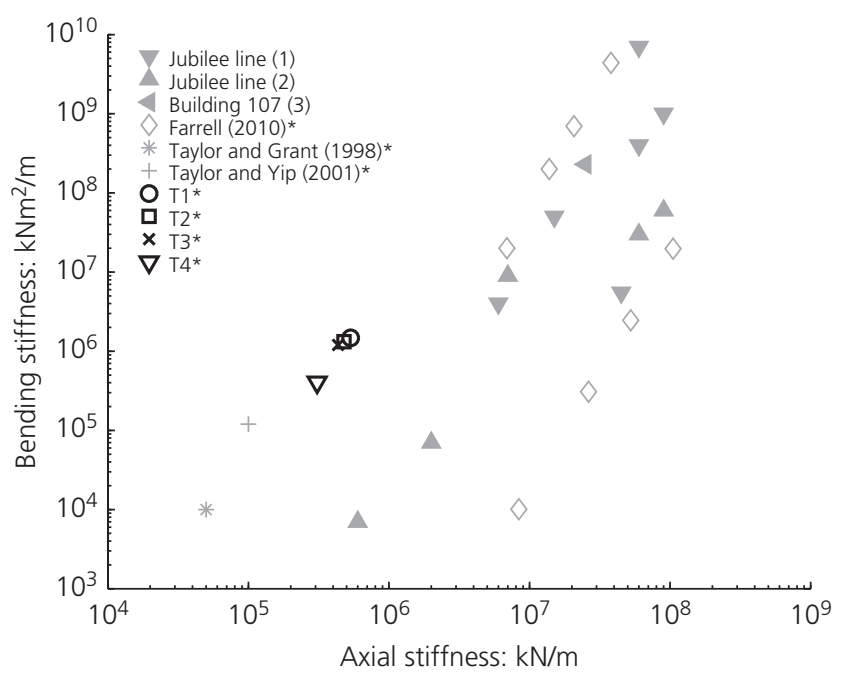

(1) Mair and Taylor (2001)

(2) Dimmock and Mair (2008)

Figure 8. Global building stiffness values of the building models compared with centrifuge tests and field data

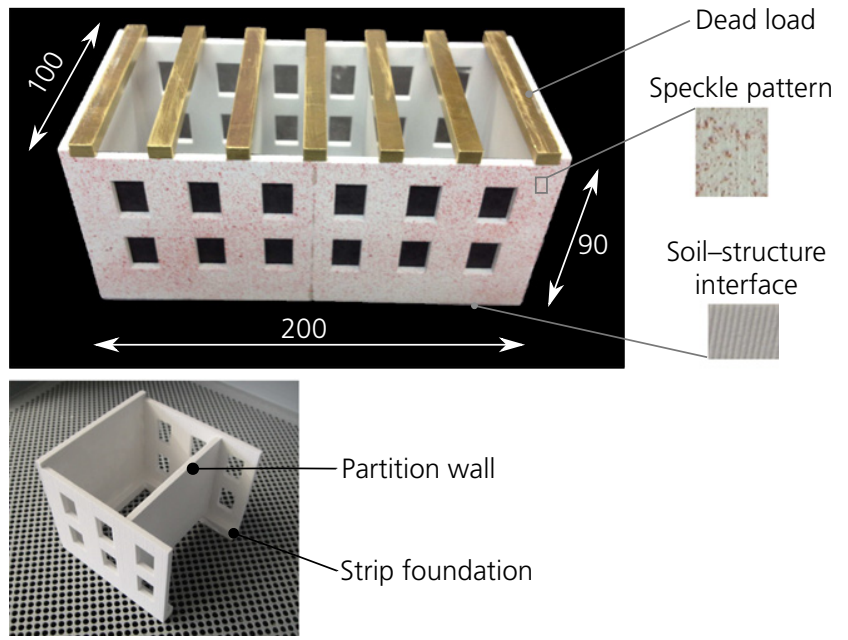

Figure 9. Three-dimensional printed building model of tests T1-T3

A cross-section of the structure model is shown in Figure 10. For all the centrifuge tests, the dimensions of the building model and the stress beneath the strip foundations were the same.

\subsection{Testing procedure}

Prior to running the centrifuge test, the $3 \mathrm{D}$ printed structure was placed on top of the soil model and the lasers and LVDTs were installed. Throughout this process, the solenoid valve (Figure 5) remained closed. After the centrifuge package was
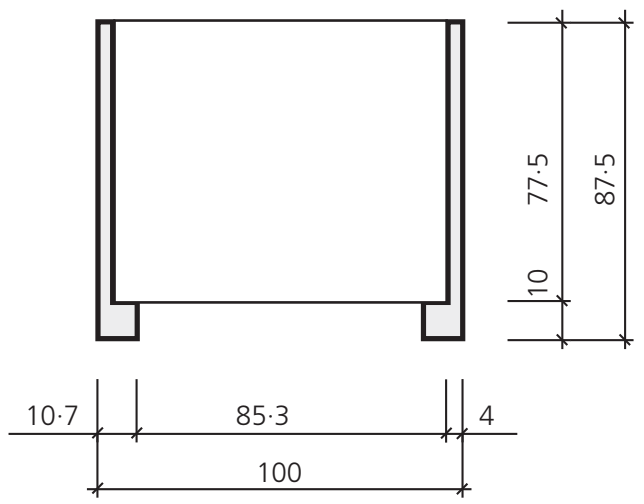

Figure 10. Cross-section of the building model in model scale (dimensions in $\mathrm{mm}$ )

loaded onto the centrifuge and the instruments were connected to the data acquisition system a standard testing procedure was followed.

- Spin-up was carried out in $10 \mathrm{~g}$ increments of up to $70 \mathrm{~g}$ and a final $5 \boldsymbol{g}$ increment. At about $6 \boldsymbol{g}$ the solenoid valve was opened and the pressure in the tunnel was controlled by the water head in the standpipe (Figure 5). At this $g$ level the vertical soil stresses at tunnel depth approximately match the initial water pressure within the tunnel, which is the result of stretching the tunnel membrane to a diameter of $82 \mathrm{~mm}$. After reaching a spin-up increment, the centrifugal acceleration was paused and the images were captured. At $75 \mathrm{~g}$, the solenoid valve was closed to connect the model tunnel to the piston (Figure 5).

- The tunnel excavation process was then simulated. Digital photographs were taken at every $0 \cdot 1 \%$ of tunnel volume loss and instrument readings were taken at $100 \mathrm{~Hz}$. Tunnel excavation simulation proceeded until a ground loss of about $26 \%$ was reached or the building collapsed.

- The centrifuge was spun down and final images were acquired.

\section{Modelling effects}

While the main objective of the research is to investigate the response of structures to tunnel excavation, this section first discusses the observations made regarding the centrifuge modelling procedure. In particular, the behaviour of the model during the spin-up is considered, followed by a brief discussion of boundary effects.

\subsection{Spin-up behaviour}

\subsubsection{Introduction}

As the centrifugal acceleration increases, the soil model experiences one-dimensional compression, which would ideally lead 
International Journal of Physical Modelling in Geotechnics Volume 18 Issue 3
Centrifuge modelling of building

response to tunnel excavation

Ritter, Giardina, DeJong and Mair to uniform soil displacements. The final state after the spin-up is typically taken as the reference condition to analyse the subsequent tunnel excavation simulation. However, the centrifuge tests presented herein developed differential soil displacements during spin-up. The reasons for this observation and its implications on the subsequent tunnel excavation are presented below. Only T1 and T2 are discussed as they reveal the main spin-up mechanisms observed.

\subsubsection{Stress imbalance and spin-up displacements}

During spin-up, the tunnel control system (Figure 5) balances the tunnel pressure $\left(\sigma_{\mathrm{t}}\right)$ with the vertical soil stresses $\left(\sigma_{\mathrm{v}}\right)$ at mid-height of the tunnel to minimise soil displacements surrounding the tunnel. However, due to density differences between the sand and water, a stress imbalance arises with vertical distance from the tunnel axis, as illustrated in Figure 11. This imbalance is larger in the horizontal direction; the horizontal soil stresses at rest $\left(\sigma_{\mathrm{h}}\right)$, which were approximated by using the assumption of Jaky (1944), are significantly smaller than the tunnel pressure (Figure 11). Additionally, the selfweight of the structure affects the stress conditions in the soil.

The stress imbalance during spin-up did induce movements of the ground and the flexible tunnel lining. Figure 12 shows the ground displacements surrounding the model tunnel after reaching $75 \mathrm{~g}$. The stress imbalance at the tunnel crown reduced the vertical soil displacements directly above the tunnel (Figure 12, left). In addition, the flexible tunnel lining moved horizontally outwards at the tunnel springlines (Figure 12, right) due to the lower horizontal soil stresses compared with the tunnel pressure. These deformations indicate that the tunnel ovalised during spin-up (Vorster, 2002). A comparison between Figures 12(a) and 12(b) depicts the influence of the building model on the spin-up behaviour. In T1, the building model was placed symmetrically above the tunnel and symmetric ground displacements were monitored (Figure 12(a)). On the contrary, the structure in test $\mathrm{T} 2$ was positioned to the right of the model tunnel which triggered higher vertical soil

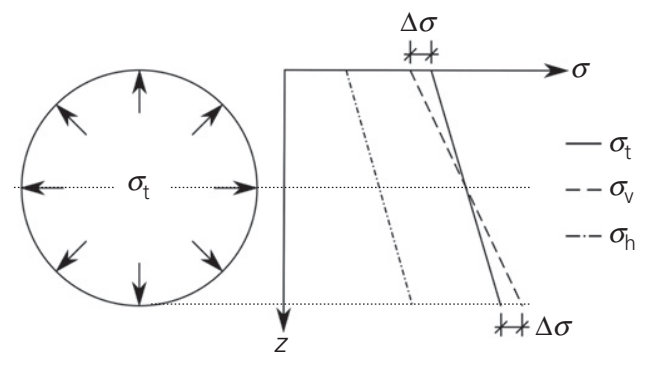

Figure 11. Comparison between tunnel pressure $\left(\sigma_{t}\right)$ and vertical $\left(\sigma_{\mathrm{v}}\right)$ and horizontal soil stresses $\left(\sigma_{\mathrm{h}}\right)$
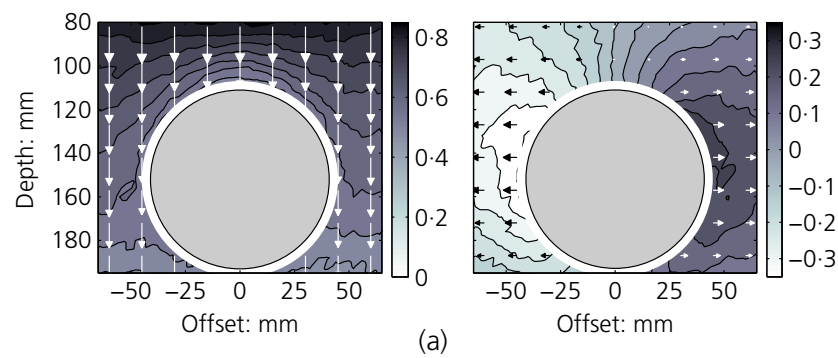

(a)
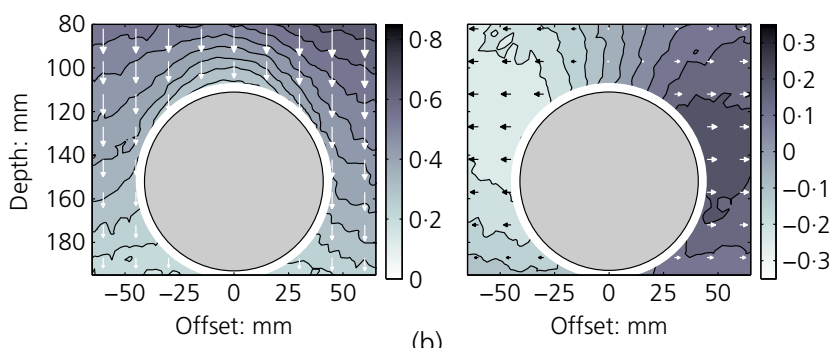

(b)

Offset: $\mathrm{mm}$

Figure 12. Vertical (left) and horizontal (right) soil displacements (in mm) after spin-up for (a) T1 and (b) T2. Settlements are positive, left horizontal displacements are negative while right horizontal displacements are positive. Displacement vectors are magnified $20 \times$

displacements above the right tunnel shoulder (Figure 12(b), left). Consequently, the tunnel lining was notably more constrained at the right-hand side of the tunnel which increased movements at the left tunnel shoulder (Figure 12(b), right).

This tunnel-soil-structure interaction during spin-up resulted in non-uniform surface soil settlements (Figure 13). Figure 13(a) and the left-hand side of Figure 13(b) shows that the settlements in the regions left and right of the tunnel were less than that above the tunnel. This observation can be explained by an increase of the soil stiffness next to the tunnel springline, which is caused by tunnel ovalisation. The identified mechanisms are in line with Vorster (2002) who used a similar experimental set-up. By contrast, the right-hand side of Figure 13(b) indicates that the spin-up soil settlements in this region are dominated by the building weight.

Figure 13 also shows that the vertical displacements of the base of the building models exceed the underlying soil settlements. Similar observations were reported by Farrell (2010). This discrepancy may be due to modelling imperfections, the applied image-based deformation measurement technique and boundary effects. Although great care was taken during the model preparation, the soil surface cannot be made perfectly level and the building model cannot be placed perfectly flushed with the underlying soil surface. As a consequence, some levelling of the soil or embedment of the building models might have caused the slightly higher building displacements observed 
International Journal of Physical Modelling in Geotechnics Volume 18 issue 3
Centrifuge modelling of building

response to tunnel excavation

Ritter, Giardina, DeJong and Mair

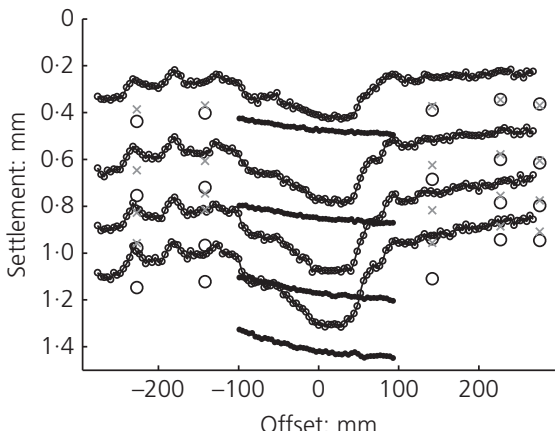

(a)

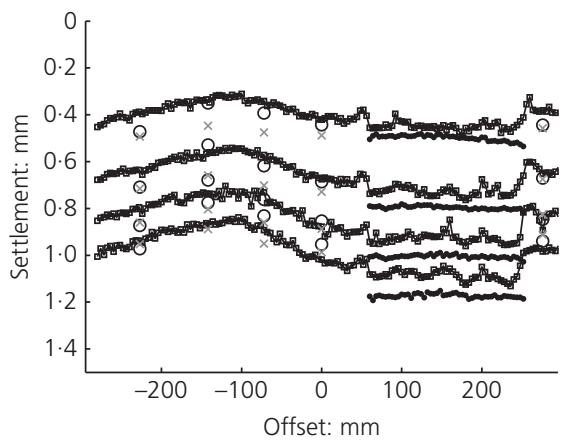

(b)

Figure 13. Spin-up surface soil and structure movements: (a) T1 and (b) T2

during spin-up. This effect might have been amplified by the GeoPIV analysis in which the displacements of the structure and the soil cannot be measured directly at the soilstructure interface. Both the soil and the structure displacements were analysed at a certain distance (i.e. $4 \mathrm{~mm}$ ) from the interface. Another possible explanation might be that the building was not completely flushed with the Perspex plane throughout the spin-up phase, and the sand immediately next to the Perspex window might have experienced boundary effects.

\subsubsection{Impact on building models}

Figure 13 depicts structure displacements during centrifuge acceleration. To evaluate the impact of the non-uniform soil settlements on the building models, the deflection ratio (DR), the slope $(s)$ and the average horizontal building strain $\left(\epsilon_{\mathrm{h}}\right)$ are estimated for the final stage of spin-up (Figure 14). While $\epsilon_{\mathrm{h}}$ is the slope of a linear function fitted to the horizontal displacements of the base of the buildings, DR and $s$ can be determined by

1. $\mathrm{DR}=\frac{\Delta_{\max }}{L}$ and

2. $s=\frac{\delta y_{A}-\delta y_{B}}{L}$

The variables of Equations 1 and 2 are defined in Figure 15. After these building movement parameters are estimated, the tensile strains induced in the building models can be computed following Burland and Wroth (1974). The maximum building tensile strain due to the spin-up displacements was estimated to be about $0.01 \%$, which is more than an order of magnitude smaller than the strain to failure of the 3D printed material (i.e. $0 \cdot 32 \%$, Table 3). This quantification of the spin-up phase tensile strains shows that the material was at the beginning of the elastic region. Thus, the soil and structure displacements at $75 \mathrm{~g}$ are valid reference conditions for the subsequent modelling of tunnel excavation. However, strains induced during spin-up need to be taken into account when investigating cracking in the structure. All results reported below are relative to the reference displacements after centrifugal acceleration.

\subsection{Boundary effects}

Various researchers have observed boundary effects caused by friction between the Perspex window and the sand model (e.g. Elshafie et al., 2013; Marshall et al., 2012). Figure 16 gives a measure of these boundary conditions by comparing the readings of the LVDTs and lasers with the obtained GeoPIV data for T2 (Figure 2(c)). Overall, the ratio between the LVDT/laser readings and the GeoPIV data $\left(\delta_{\mathrm{LVDTs} / \text { lasers }} / \delta_{\mathrm{GeoPIV}}\right)$ was about $1 \cdot 12$ for $\mathrm{T} 2$. This value is indicative, but varied slightly between the different tests. Figure 16 shows that the difference between GeoPIV displacements and LVDT/laser measurements increases with volume loss. Similar results were reported by Elshafie et al. (2013), Farrell (2010) and Marshall et al. (2009). Marshall et al. (2009) have found that the shape of the settlement profiles is not significantly affected by boundary friction. These findings confirm the reliability of the imagebased deformation measurement technique and indicate boundary effects similar to previous research.

\section{Results of tunnel excavation simulation}

This section evaluates the soil-structure interaction data from the new centrifuge tests through comparison to previous literature. To verify that the experimental set-up realistically models all parts of this tunnel-soil-structure interaction problem, volume changes in the soil, the effect of the building position on the ground displacements and the impact of facade openings on the building response are addressed. The given results were obtained by GeoPIV.

\subsection{Volume change in drained conditions}

Previous researchers have reported that in drained soils, the ground loss at surface is less than the ground loss surrounding 


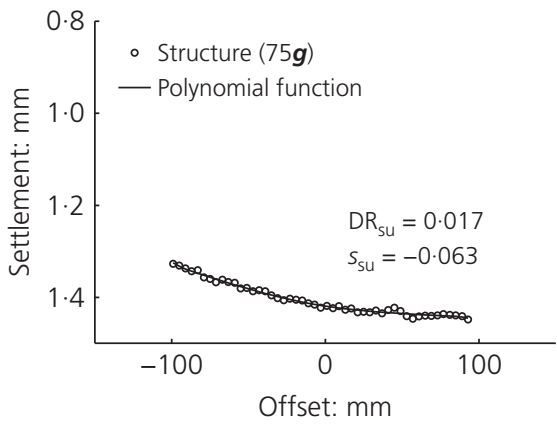

(a)

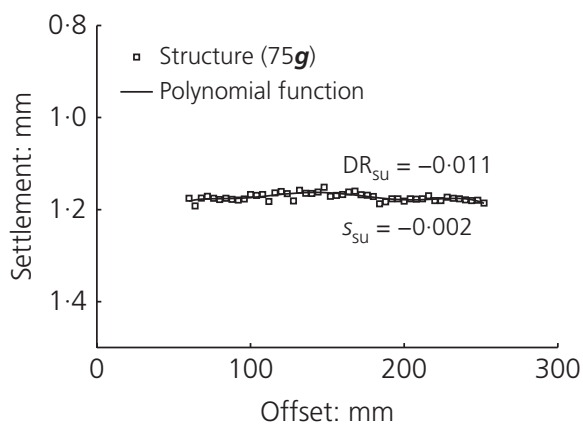

(c)

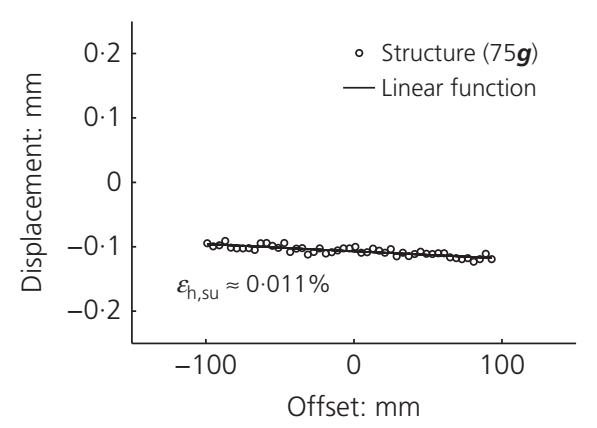

(b)

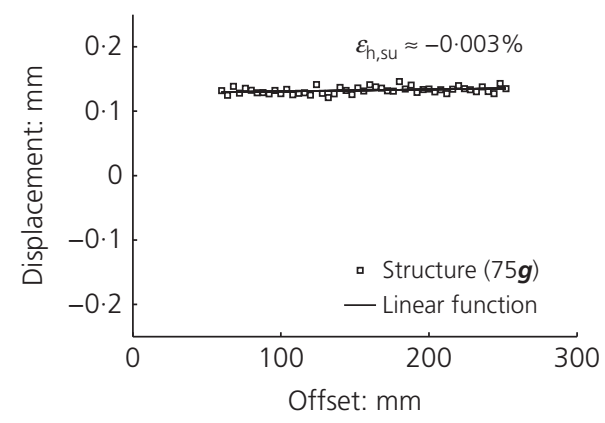

(d)

Figure 14. Structure response after spin-up: (a) vertical displacements of T1, (b) horizontal displacements of T1, (c) vertical displacements of T2 and (d) horizontal displacements of T2. Deflection ratio (DR), slope (s) and average horizontal base strain $\left(\epsilon_{h}\right.$, tensile strains are negative) are presented at $\mathbf{7 5} \boldsymbol{g}$

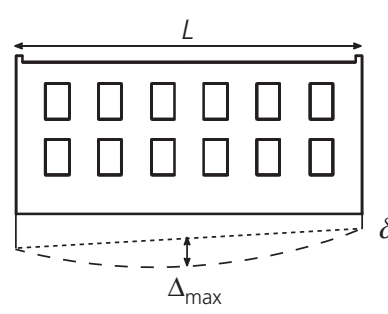

(a)

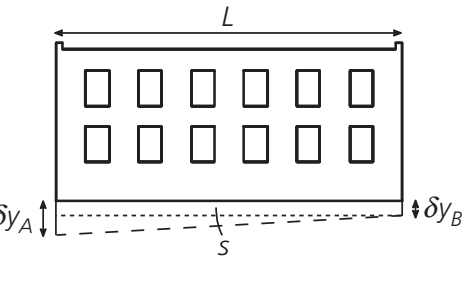

(b)
Figure 15. Building movement parameters: (a) deflection ratio $(\mathrm{DR})$ and $(\mathrm{b})$ slope $(s)$

the tunnel (Cording and Hansmire, 1975; Marshall et al., 2012). This volume change can be related to shearing deformations, which lead to compression and dilation in the soil above the tunnel (Marshall et al., 2012). Figure 17 presents the modelled tunnel volume loss $\left(V_{1, \mathrm{t}}\right)$ and the soil surface volume loss $\left(V_{1, \mathrm{~s}}\right)$, calculated through integration of surface settlement profiles that were obtained by GeoPIV. As a consequence of the boundary conditions discussed above (Figure 16), the determined soil volume losses present a slightly lower value

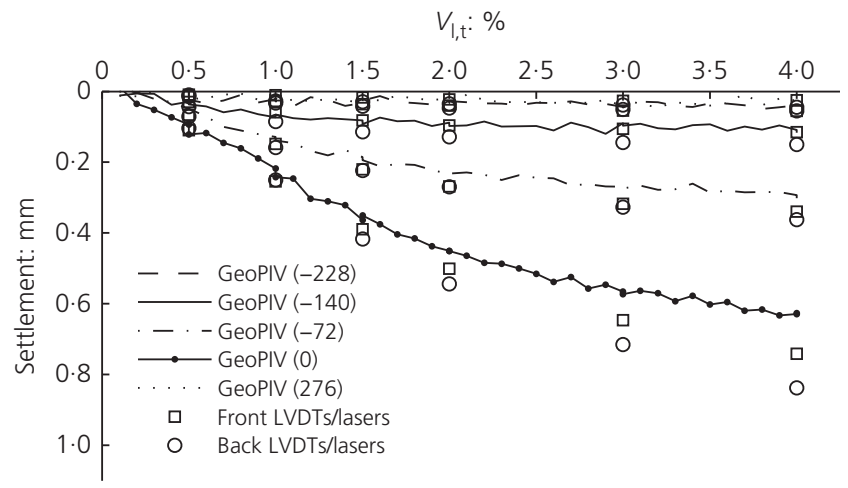

Figure 16. Comparison between LVDTs/lasers and GeoPIV measurements of test T2. The values in the parentheses indicate the offset $(\mathrm{mm})$ from the tunnel centreline of the associated LVDT/laser (Figure 2(c))

than measured with distance from the Perspex. The experimentally obtained data generally show good agreement with the relationship proposed by Marshall et al. (2012) for a greenfield test with the same soil properties. Nevertheless, for the 
International Journal of Physical Modelling in Geotechnics Volume 18 Issue 3
Centrifuge modelling of building

response to tunnel excavation

Ritter, Giardina, DeJong and Mair

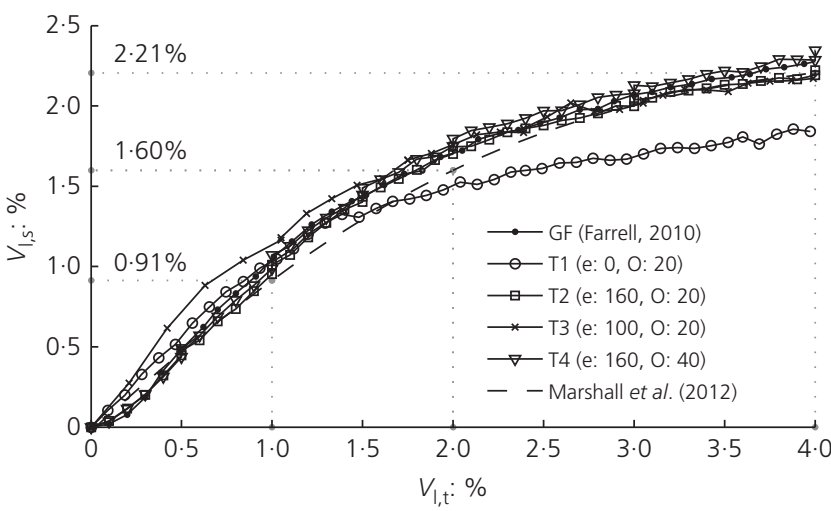

Figure 17. Tunnel volume loss $\left(V_{1, t}\right)$ compared with measured surface soil volume loss $\left(V_{l, s}\right)$ for tests with different eccentricity $(e)$ and facade openings $(O)$

structure placed symmetrically above the tunnel (T1), the surface volume loss diverges after about $1.5 \%$ of tunnel volume loss. This difference is likely to be related to a gap formation (Farrell, 2010) beneath the base of the structure that caused a decrease of the mean stresses in the soil, and thus dilation became more pronounced.

Figure 17 demonstrates that a range of volume losses can be investigated in a single centrifuge test. The soil surface volume loss, which is typically measured in the field, is considerably lower than the modelled tunnel volume loss. For instance, a tunnel volume loss of about $2 \cdot 0 \%$ results in a surface soil volume loss of about $1.6 \%$, which is similar to typical design criteria for shotcrete lining tunnels (i.e. $1 \cdot 5 \%$ ). Therefore, the data below are presented for a tunnel volume loss of $2 \cdot 0 \%$.

\subsection{Effect of building position}

The current methods of predicting potential building damage consider the location of the building relative to the tunnel. To quantify the effect of the building position, three equal building models were tested in different regions of the tunnellinginduced settlement trough. The discussed centrifuge tests are T1, T2 and T3 (Figure 1) along with a previous greenfield test (Farrell, 2010).

\subsubsection{Surface ground movements}

Figure 18 shows that the soil-structure interaction considerably modified the ground surface displacements. The data in Figure 18 (left) indicate a notable reduction in the curvature of the settlement profiles beneath the structures. Figure 18 (right) shows that the buildings restrained the horizontal ground displacements.
The building location clearly affected the vertical ground movements. Structures located symmetrically to the tunnel (T1) increased the greenfield vertical displacements beneath the edges of the building while settlements reduced beneath the centre (Figure 18(a), left). The embedment of the structure at the trough shoulders was accompanied by a gap that formed underneath the centre of the structure and the soil surface. As a consequence, the contact area of the foundation reduced and the bearing pressure increased in the regions where the foundations were in contact with the soil, causing the embedment. Potts and Addenbrooke (1997) presented similar surface settlement profiles for structures placed at zero eccentricity. By contrast, when the structure was located asymmetrically to the model tunnel the vertical displacements increased underneath the entire building length (Figure 18(b), left and Figure 18(c), left). For the structure in the transition region (T3), the maximum surface settlements (which occurred above the tunnel centreline) exceeded the greenfield measurements (Figure 18(c), left). This increase in settlements was due to a rigid body rotation and embedment underneath the left corner of the structure, similar to the embedment effect discussed above. Liu et al. (2001) have reported similar results of large vertical settlements and serious tilt when a corner of a structure is located directly above the tunnel.

Horizontal soil displacements were also affected by the location of the building above the tunnel. Buildings placed symmetrically lowered the horizontal greenfield displacements beneath the entire extent of the structure (Figure 18(a), right). Meanwhile, structures in an asymmetric position reduced the horizontal soil displacements closer to the tunnel, but caused increased horizontal movements further from the tunnel (Figures 18(b) and 18(c), right). The greater horizontal soil movements can be related to the friction at the soil-structure interface. The structure transferred shear stress to the soil beneath, and the soil was dragged by the structure. Overall, the data suggest that differential horizontal soil displacements are significantly reduced due to the presence of a building. Similar conclusions have been reached by Dimmock and Mair (2008), Elshafie et al. (2013), Farrell and Mair (2012) and Viggiani and Standing (2001).

\subsection{Effect of facade openings}

To evaluate the effect of facade openings on the building's response to tunnelling subsidence, results from $\mathrm{T} 2$ (20\% of openings) and T4 (40\% of openings) were compared. At each level of volume loss, the DR was calculated by first fitting polynomials to smooth the vertical displacement data of the centrifuge tests to prevent overestimation of the DRs. A fifth degree polynomial was used for fitting because it was the minimum degree polynomial that minimised the fitting error. The hogging and sagging zones (for the greenfield and 

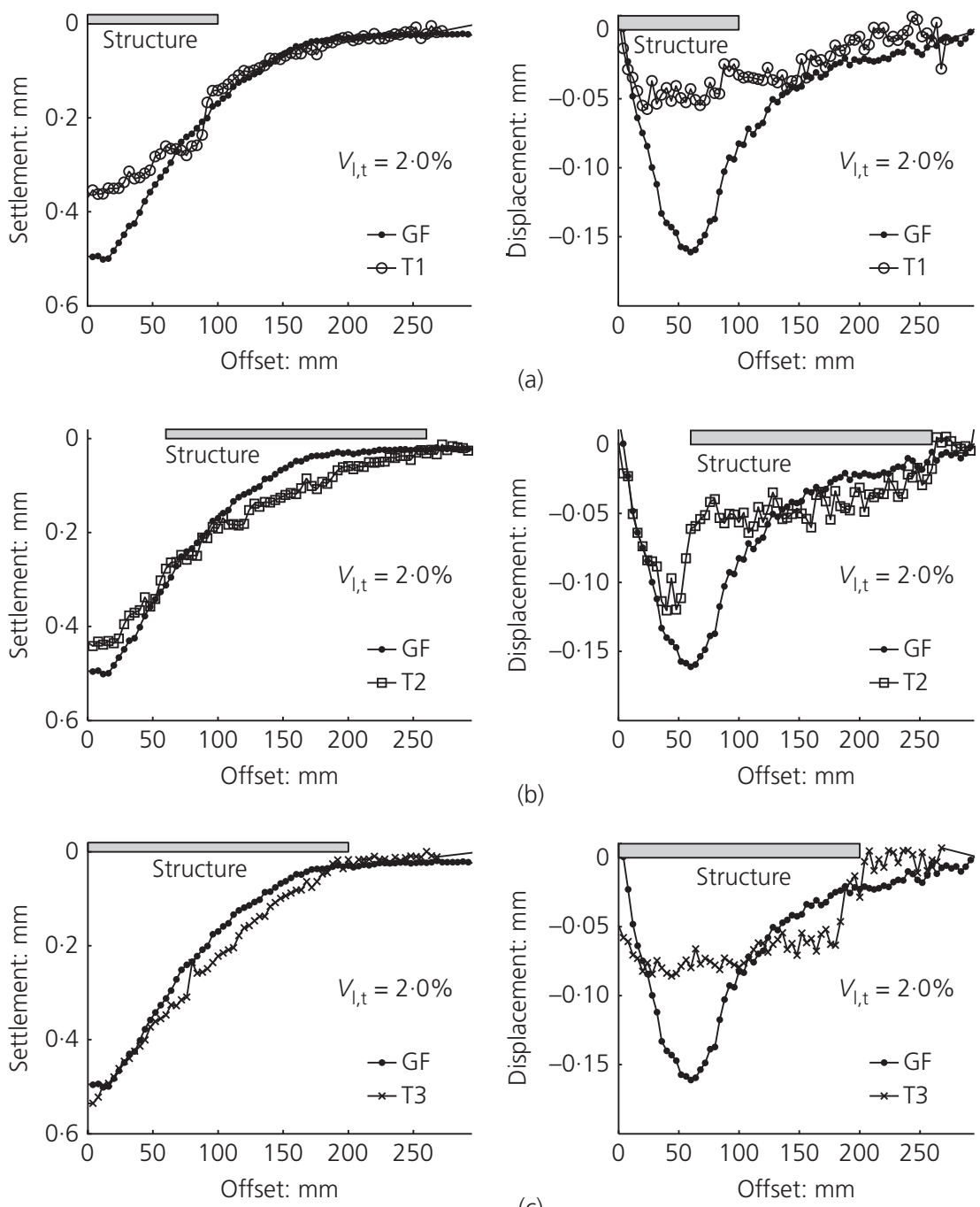

Figure 18. Surface soil displacement profiles at a tunnel volume loss $\left(V_{1, t}\right)$ of $2 \cdot 0 \%$. The left column presents the settlements while the right column shows the horizontal displacements. Horizontal movements towards the left are negative. Greenfield data (GF) is given for reference (Farrell, 2010): (a) T1 (b) T2 (c) T3

soil-structure tests) were limited by the inflection point of modified Gaussian curves that were fitted to the associated surface soil displacement profiles. The inflection points were obtained for the different volume loss increments investigated. For tunnel volume losses of $<1 \cdot 5 \%$, very short sections of the buildings were classified as sagging regions based on the inflection point division, but these were inconsequential and were neglected in the following analysis. At tunnel volume losses of $>1.5 \%$, the entire building was located in the hogging region defined by the inflection point.

The ratio between the hogging DR at the base of the building and the corresponding greenfield $\mathrm{DR}\left(\mathrm{DR}^{\mathrm{GF}}\right)$ is called the modification factor of the DR $\left(M^{\mathrm{DR}}\right)$. Figure 19 compares the $M^{\mathrm{DR}}$ of T2 with T4, and illustrates that $M^{\mathrm{DR}}$ increased with the amount of facade openings. For T4, $M^{\mathrm{DR}}$ also increased with volume loss as $V_{1, \mathrm{t}}$ increased to more than $\sim 2 \cdot 0 \%$. This effective decrease in building stiffness (i.e. increase in $M^{\mathrm{DR}}$ ) with volume loss can be explained due to the onset of building damage when micro-cracks propagate through the building, while a decrease of $M^{\mathrm{DR}}$ can be explained by a decrease of the soil stiffness (Farrell, 2010).

Predicting building response to tunnelling-induced subsidence frequently relates the equivalent bending stiffness, EI, to a representative soil stiffness, $E_{\mathrm{s}}$ (Franzius et al., 2006; Goh and 
Centrifuge modelling of building response to tunnel excavation

Ritter, Giardina, DeJong and Mair

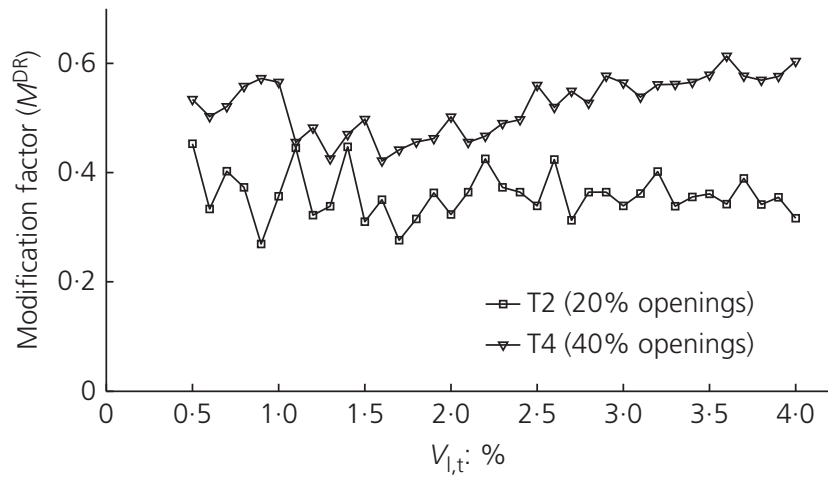

Figure 19. Variation of modification factor of DR with tunnel volume loss for T2 (20\% of openings) and T4 (40\% of openings)

Mair, 2011; Mair, 2013; Potts, 1976). Goh and Mair (2011) proposed the following relative bending stiffness

3. $\rho_{\mathrm{hog}}=\frac{\mathrm{EI}}{E_{\mathrm{s}} L_{\mathrm{hog}}^{3}}, \quad \rho_{\mathrm{sag}}=\frac{\mathrm{EI}}{E_{\mathrm{s}} L_{\mathrm{sag}}^{3}}$

where $L_{\mathrm{hog}}$ and $L_{\mathrm{sag}}$ are the building length in hogging and sagging. In Figure 20, the observed $M^{\mathrm{DR}}$ of $\mathrm{T} 2$ and $\mathrm{T} 4$ are plotted with respect to relative bending stiffness predictions (calculated by either reducing EI due to window openings (Melis and Rodriguez Ortiz, 2001) or ignoring openings) on the design chart of Goh and Mair (2011) and Mair (2013). Figure 20 indicates that the obtained data are within the accepted design guidelines.

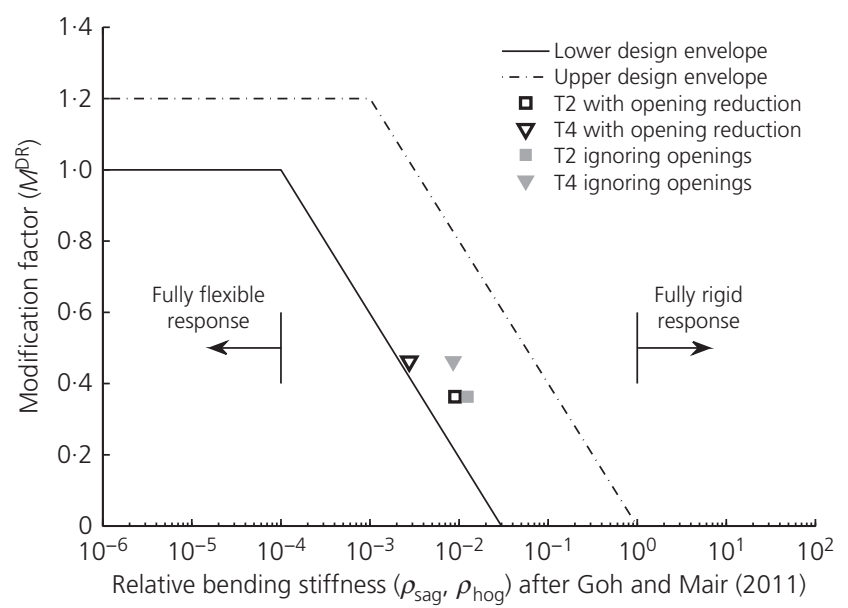

Figure 20. Relative bending stiffness (Goh and Mair, 2011; Mair, 2013). The observations are shown for a tunnel volume loss of $2.0 \%$

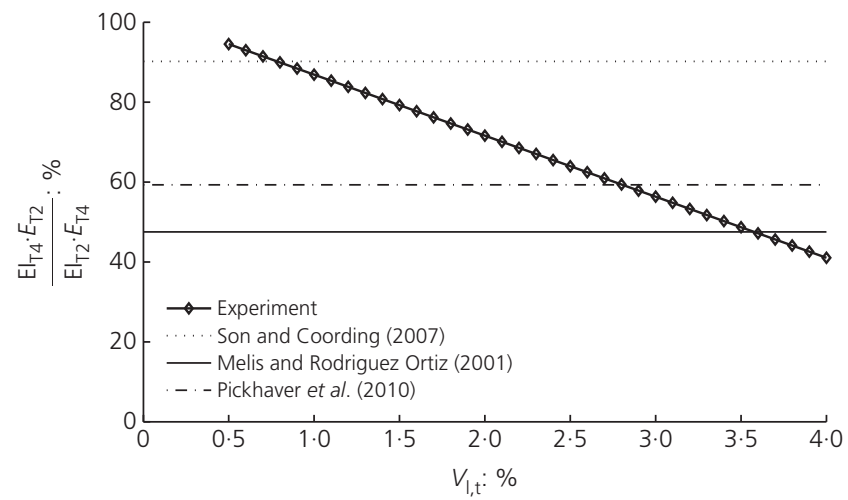

Figure 21. Normalised ratio between the global building bending stiffness of T4 and T2

To further investigate the impact of facade openings on the building stiffness, EI values were back-calculated by assuming that the measured $M^{\mathrm{DR}}$ of T2 and T4 (Figure 19) are on the same design envelope of Goh and Mair (2011) and Mair (2013) and solving for EI in Equation 3. These hypothetical EI values are then normalised by the average Young's modulus of the corresponding 3D printed building model (Table 3) to account for differences in the $3 \mathrm{D}$ printed material properties. Figure 21 relates the normalised bending stiffness of T4 to T2, which was smoothed by a linear regression, alongside the literature that is widely adopted to reduce EI due to facade openings. The literature values were obtained by considering the material properties and openings of the corresponding building models. The experimental result shows that an increase of facade openings notably reduces the bending stiffness as the volume loss increases, which is currently neglected in the literature. However, for volume losses $<3.5 \%$, both Melis and Rodriguez Ortiz (2001) and Pickhaver et al. (2010) provide conservative predictions, while the Son and Cording (2007) prediction corresponded to a volume loss of $\sim 0 \cdot 75 \%$.

\section{Conclusions}

A centrifuge modelling procedure to study the mechanism of tunnelling on surface structures was presented. Three-dimensional printed building models allowed modelling of building details such as window openings, strip foundations and partition walls at a scale factor of 1:75. Four-point bending tests were carried out to obtain 3D printed material properties. The material demonstrated brittle behaviour, and balancing of the building layout enabled building stiffness values comparable to case histories.

The interaction between the soil, the model tunnel and the surface structures as $\boldsymbol{g}$ level increases was quantified. 
International Journal of Physical Modelling in Geotechnics Volume 18 Issue 3
Centrifuge modelling of building

response to tunnel excavation

Ritter, Giardina, DeJong and Mair
The spin-up data demonstrated that the tunnelling simulation technique resulted in non-uniform surface settlements. Building tensile strains induced during spin-up were not negligible, but the 3D printed material remained elastic. Results of the tunnel excavation simulation showed that volume changes in the drained soil conditions, the effect of the building position on ground movements and the influence of facade openings on the building response were modelled in great detail. These results provide confidence that the physical modelling set-up realistically replicates soil-structure interaction during tunnelling, and that this set-up can be usefully applied in continued research into the effect of building details (e.g. building layout, aspect ratio and facade openings) on the response of buildings to tunnelling.

\section{Acknowledgements}

The authors are grateful to EPSRC grant EP/K018221/1 and Crossrail for the financial support. They also acknowledge Dr Ruadhri P. Farrell for sharing experimental data and the staff of the Schofield Centre for their contributions to the experimental preparation. The associated research data are available at http://dx.doi.org/10.17863/CAM.803.

\section{REFERENCES}

Al Heib M, Emeriault F, Caudron M, Nghiem L and Hor B (2013) Large-scale soil-structure physical model (1g)-assessment of structure damages. International Journal of Physical Modelling in Geotechnics 13(4): 138-152, http://dx.doi.org/10.1680/ ijpmg.13.00007.

Asadi-Eydivand M, Solati-Hashjin M, Farzad A and Osman NAA (2016) Effect of technical parameters on porous structure and strength of 3D printed calcium sulfate prototypes. Robotics and Computer-Integrated Manufacturing 37: 57-67, https://doi.org/ 10.1016/j.rcim.2015.06.005.

ASTM (1986) D 790M-86 II: Standard test methods for flexural properties of unreinforced and reinforced plastics and electrical insulating. ASTM International, West Conshohocken, PA, USA.

Burd H, Houslby G, Augarde C and Liu G (2000) Modelling tunnelling-induced settlement of masonry buildings. Proceedings of the Institution of Civil Engineers - Geotechnical Engineering 143(1): 17-30, http://dx.doi.org/10.1680/geng.2000. 143.1.17.

Burland J and Wroth C (1974) Settlement of buildings and associated damage. In Proceedings of Conference on Settlement of Structures. Pentech Press, Cambridge, UK, pp. 611-654.

Caporaletti P, Burghignoli A and Taylor R (2005) Centrifuge study of tunnel movements and their interaction with structures. In Geotechnical Aspects of Underground Construction in Soft Ground: Proceedings of the 5th International Symposium TC28, Amsterdam, the Netherlands (Bakker KJ, Bezuijen A, Broere W and Kwas EA (eds)). CRC Press, London, UK, p. 99-106.

Chan D (2012) 3D Printing of Structural Scale Models. University of Cambridge, Cambridge, UK, UROP final report.
Chan D (2013) Investigation of Tunnelling-Induced Building Settlements Using 3D-Printed Models. Fourth-Year Undergraduate Project. University of Cambridge, Cambridge, UK.

Cording E and Hansmire W (1975) Displacements around soft ground tunnels. In General Report, Session 4, 5th Panamerican Conference on Soil Mechanics and Foundation Engineering, Buenos Aires, Argentina, pp. 571-632.

DeJong MJ and Vibert C (2012) Seismic response of stone masonry spires: computational and experimental modeling. Engineering Structures 40: 566-574, https://doi.org/10.1016/ j.engstruct.2012.03.001.

Dimmock PS and Mair RJ (2008) Effect of building stiffness on tunnelling-induced ground movement. Tunnelling and Underground Space Technology 23(4): 438-450.

Elshafie M, Choy C and Mair R (2013) Centrifuge modeling of deep excavations and their interaction with adjacent buildings. ASTM Geotechnical Testing Journal 36(5): 637-648, https://doi.org/ 10.1520/GTJ20120209.

Fargnoli V, Gragnano C, Boldini D and Amorosi A (2015) 3D numerical modelling of soil-structure interaction during EPB tunnelling. Géotechnique 65(1): 23-37, http://dx.doi.org/ 10.1680/geot.14.P.091.

Farrell R (2010) Tunnelling in Sands and the Response of Buildings. PhD thesis, University of Cambridge, Cambridge, UK.

Farrell R and Mair R (2012) Centrifuge modelling of the response of buildings to tunnelling. In Proceedings of the International Symposium on Geotechnical Aspects of Underground Construction in Soft Ground (Viggiani G (ed.)), CRC Press, Rome, Italy, pp. 343-351.

Farrell R, Mair R, Sciotti A, Pigorini A and Ricci M (2011) The response of buildings to tunnelling: a case study. In Proceedings of $7 \mathrm{th}$ International Symposium on Geotechnical Aspects of Underground Construction in Soft Ground, Rome, Italy (Viggiani G (ed.)), CRC Press, Rome, Italy.

Farzadi A, Solati-Hashjin M, Asadi-Eydivand M and Osman NAA (2014) Effect of layer thickness and printing orientation on mechanical properties and dimensional accuracy of 3D printed porous samples for bone tissue engineering. PLoS One 9(9): 1-14.

Farzadi A, Waran V, Solati-Hashjin M et al. (2015) Effect of layer printing delay on mechanical properties and dimensional accuracy of $3 \mathrm{D}$ printed porous prototypes in bone tissue engineering. Ceramics International 41(7): 8320-8330.

Feng P, Meng X, Chen JF and Ye L (2015) Mechanical properties of structures 3D printed with cementitious powders. Construction and Building Materials 93: 486-497, https://doi.org/10.1016/j. conbuildmat.2015.05.132.

Franzius JN, Potts DM and Burland JB (2006) The response of surface structures to tunnel construction. Proceedings of the Institution of Civil Engineers - Geotechnical Engineering 159(1): 3-17, http://dx.doi.org/10.1680/ geng.2006.159.1.3.

Frischmann W, Hellings J, Gittoes G and Snowden C (1994) Protection of the Mansion House against damage caused by ground movements due to the Docklands Light Railway Extension. Proceedings of the Institution of Civil Engineers - Geotechnical Engineeringol 107, pp. 65-76, http://dx.doi.org/10.1680/ igeng.1994.26374.

Gharaie SH, Morsi Y and Masood SH (2013) Tensile properties of processed 3D printer ZP150 powder material. Advanced Materials Research 699: 813-816.

Giardina G, Marini A, Hendriks MAN et al. (2012) Experimental analysis of a masonry façade subject to tunnelling-induced settlement. 
International Journal of Physical Modelling in Geotechnics Volume 18 Issue 3
Centrifuge modelling of building

response to tunnel excavation

Ritter, Giardina, DeJong and Mair
Engineering Structures 45: 421-434, https://doi.org/10.1016/j. engstruct.2012.06.042.

Giardina G, DeJong MJ and Mair RJ (2015a) Interaction between surface structures and tunnelling in sand: centrifuge and computational modelling. Tunnelling and Underground Space Technology 50: 465-478, https://doi.org/10.1016/ j.tust.2015.07.016

Giardina G, Hendriks M and Rots J (2015b) Damage functions for the vulnerability assessment of masonry buildings subjected to tunneling. Journal of Structural Engineering 141(9): http://dx.doi.org/10.1061/(ASCE)ST.1943-541X.0001162.

Giardina G, Hendriks MAN and Rots JG (2015c) Sensitivity study on tunnelling induced damage to a masonry façade. Engineering Structures 89: 111-129, https://doi.org/10.1016/j.engstruct.2015. 01.042 .

Goh KH and Mair RJ (2011) Building damage assessment for deep excavations in Singapore and the influence of building stiffness. Geotechnical Engineering Journal of the SEAGS \& AGSSEA 42(3): $1-12$.

Jacobsz SW (2002) The Effects of Tunnelling on Piled Foundations. $\mathrm{PhD}$ thesis, University of Cambridge, Cambridge, UK.

Jaky J (1944) The coefficient of earth pressure at rest. Journal of the Society of Hungarian Architects and Engineers 78(22): 355-358.

Kim H, Hwang E and Kim Z (2006) The model tests for the damage assessment of brick structures in urban tunnelling. Tunnelling and Underground Space Technology 21(3): 305-305.

Knappett J, Reid C, Kinmond S and OReilly K (2010) Small-scale modeling of reinforced concrete structural elements for use in a geotechnical centrifuge. Journal of Structural Engineering 137(11): 1263-1271.

Liang T, Knappett J and Bengough A (2013) Scale modelling of plant root systems using 3-D printing. In ICPMG2014 Physical Modelling in Geotechnics: Proceedings of the 8th International Conference on Physical Modelling in Geotechnics 2014 (ICPMG2014), Perth, Australia (Gaudin C and White D (eds)), CRC Press, Perth, Australia, p. 361.

Liang T, Knappett J and Duckett N (2015) Modelling the seismic performance of rooted slopes from individual root-soil interaction to global slope behaviour. Géotechnique 65(12): 995-1009, http://dx.doi.org/10.1680/jgeot.14.P.207.

Liu G, Houlsby G and Augarde C (2001) 2-dimensional analysis of settlement damage to masonry buildings caused by tunnelling. Structural Engineer 79(1): 19-25.

Loganathan N, Poulos H and Stewart D (2000) Centrifuge model testing of tunnelling-induced ground and pile deformations. Géotechnique 50(3): 283-294, http://dx.doi.org/10.1680/ geot.2000.50.3.283.

Madabhushi S, Houghton N and Haigh S (2006) A new automatic sand pourer for model preparation at University of Cambridge. In Proceedings of the 6th International Conference on Physical Modelling in Geotechnics ( $\mathrm{Ng}$, Zhang and Wang (eds)), Taylor \& Francis Group, London, UK, pp. 217-222.

Mair R (2013) Tunnelling and deep excavations: ground movements and their effects. In Proceedings of the 15th European Conference on Soil Mechanics and Geotechnical Engineering - Geotechnics of Hard Soils-Weak Rocks (Part 4) (Anagnostopoulos A, Pachakis M, Tsatsanifos C (eds)). IOS Press, Athens, Greece, pp. $39-70$

Mair R, Phillips R, Schofield A and Taylor R (1984) Application of centrifuge modelling to the design of tunnels and excavations in soft clay. In Proceedings of the Symposium on the Application of
Centrifuge Modelling to Geotechnical Design, Manchester, UK (Craig WH (ed.)). AA Balkema, the Netherlands, pp. 357-380.

Marshall AM, Elkayam I and Klar A (2009) Ground behaviour above tunnels in sand-DEM simulations versus centrifuge test results. In Euro: Tun 2009, Proceedings of the 2nd International Conference on Computational Methods in Tunnelling, Bochum, Germany (Meschke G, Beer G, Eberhardsteiner J, Hartmann D and Thewes M (eds)), Aedificatio Verlag, Bochum, Germany, pp. $9-11$

Marshall A, Farrell R, Klar A and Mair R (2012) Tunnels in sands: the effect of size, depth and volume loss on greenfield displacements. Géotechnique 62(5): 385-399, http://dx.doi.org/ 10.1680/geot.10.P.047.

Melis M and Rodriguez Ortiz J (2001) Consideration of the stiffness of buildings in the estimation of subsidence damage by EPB tunnelling in the Madrid Subway. In Proceedings of the International Conference on Response of Buildings to Excavation Induced Ground Movements, London, UK (Jardine FM (ed.)), CIRIA, London, UK, pp. 17-18.

Netzel HD (2009) Building Response Due to Ground Movements. $\mathrm{PhD}$ thesis, Delft University of Technology, Delft, The Netherlands.

Pickhaver J, Burd H and Houlsby G (2010) An equivalent beam method to model masonry buildings in 3D finite element analysis. Computers and Structures 88(19): 1049-1063.

Potts DM (1976) Behaviour of Lined and Unlined Tunnels in Sand. $\mathrm{PhD}$ thesis, University of Cambridge, Cambridge, UK.

Potts D and Addenbrooke T (1997) A structure's influence on tunnelling induced ground movements. Proceedings of the Institution of Civil Engineers - Geotechnical Engineering 125(2): 109-125, http://dx.doi.org/10.1680/ igeng.1997.29233.

Sachs E, Cima M and Cornie J (1990) Three-dimensional printing: rapid tooling and prototypes directly from a CAD model. CIRP Annals - Manufacturing Technology 39(1): 201-204.

Schofield AN (1980) Cambridge geotechnical centrifuge operations. Géotechnique 30(3): 227-268, http://dx.doi.org/10.1680/ geot.1980.30.3.227.

Shahin HM, Nakai T, Zhang F, Kikumoto M and Nakahara E (2011) Behavior of ground and response of existing foundation due to tunneling. Soils and Foundations 51(3): 395-409.

Son M (2015) Response analysis of nearby structures to tunnelinginduced ground movements in clay soils. Tunnelling and Underground Space Technology 56: 90-104, https://doi.org/10.1016/ j.tust.2016.01.032.

Son M and Cording EJ (2005) Estimation of building damage due to excavation-induced ground movements. Journal of Geotechnical and Geoenvironmental Engineering 131(2): 162-177.

Son M and Cording EJ (2007) Evaluation of building stiffness for building response analysis to excavation-induced ground movements. Journal of Geotechnical and Geoenvironmental Engineering 133(8): 995-1002.

Tan FSC (1990) Centrifuge and Theoretical Modelling of Conical Footings on Sand. $\mathrm{PhD}$ thesis, University of Cambridge, Cambridge, UK

Taylor R and Grant R (1998) Centrifuge modelling of the influence of surface structures on tunnelling induced ground movements. In Tunnels and Metropolises (Negro A and Ferreira AA (eds)). Balkema, the Netherlands, pp. 261-266.

Taylor R and Yip D (2001) Centrifuge modelling on the effect of a structure on tunnelling-induced ground movements. In International Conference on Response of Buildings to 
Excavation-Induced Ground Movements, London, UK (Jardine FM (ed.)). CIRIA, London, UK, pp. 601-611.

Viggiani G and Standing J (2001) The treasury. In Building Response to Tunnelling: Case Studies from Construction of the Jubilee Line

Extension (Burland JB, Standing JR and Jardine FM (eds)). Ciria and Thomas Telford, London, UK, vol. 2, pp. 401-432.

Vorster T (2002) The Effects of Tunnelling on Buried Pipes. PhD thesis, University of Cambridge, Cambridge, UK.
Vu MN, Broere W and Bosch J (2015) Effects of cover depth on ground movements induced by shallow tunnelling. Tunnelling and Underground Space Technology 50: 499-506, https://doi.org/ 10.1016/j.tust.2015.09.006.

White D, Take W and Bolton M (2003) Soil deformation measurement using particle image velocimetry (PIV) and photogrammetry. Géotechnique 53(7): 619-632, http://dx.doi.org/10.1680/geot.2003. 53.7.619.

\section{How can you contribute?}

To discuss this paper, please email up to 500 words to the editor at journals@ice.org.uk. Your contribution will be forwarded to the author(s) for a reply and, if considered appropriate by the editorial board, it will be published as discussion in a future issue of the journal.

International Journal of Physical Modelling in Geotechnics relies entirely on contributions from the civil engineering profession (and allied disciplines). Information about how to submit your paper online is available at www. icevirtuallibrary.com/page/authors, where you will also find detailed author guidelines. 